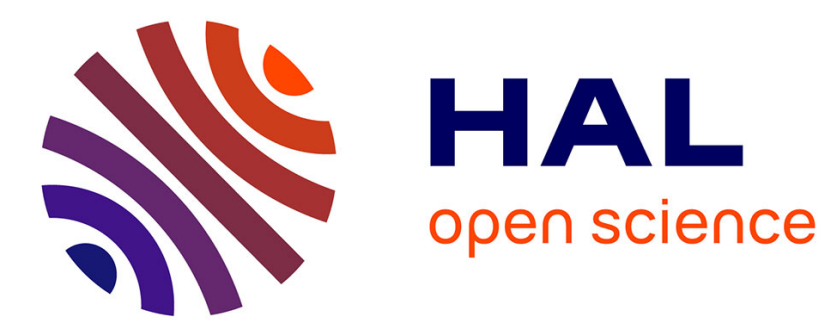

\title{
Group size, grooming and fission in primates: A modeling approach based on group structure
}

Cédric Sueur, Jean-Louis Deneubourg, Odile Petit, Iain D. Couzin

\section{To cite this version:}

Cédric Sueur, Jean-Louis Deneubourg, Odile Petit, Iain D. Couzin. Group size, grooming and fission in primates: A modeling approach based on group structure. Journal of Theoretical Biology, 2011, 273 (1), pp.156. 10.1016/j.jtbi.2010.12.035 . hal-00669205

\section{HAL Id: hal-00669205 https://hal.science/hal-00669205}

Submitted on 12 Feb 2012

HAL is a multi-disciplinary open access archive for the deposit and dissemination of scientific research documents, whether they are published or not. The documents may come from teaching and research institutions in France or abroad, or from public or private research centers.
L'archive ouverte pluridisciplinaire HAL, est destinée au dépôt et à la diffusion de documents scientifiques de niveau recherche, publiés ou non, émanant des établissements d'enseignement et de recherche français ou étrangers, des laboratoires publics ou privés. 


\section{Author's Accepted Manuscript}

Group size, grooming and fission in primates: A modeling approach based on group structure

Cédric Sueur, Jean-Louis Deneubourg, Odile Petit, Iain D. Couzin

PII: S0022-5193(10)00690-9

DOI: doi:10.1016/j.jtbi.2010.12.035

Reference: YJTBI 6304

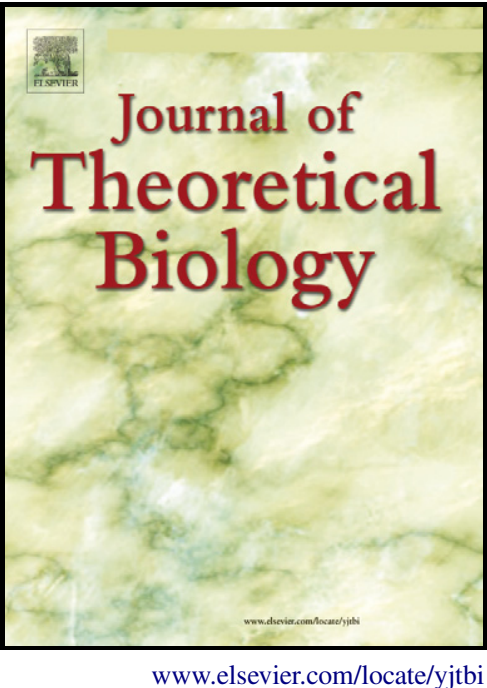

To appear in: $\quad$ Journal of Theoretical Biology

Received date: $\quad$ 29 June 2010

Revised date: $\quad 15$ December 2010

Accepted date: 21 December 2010

Cite this article as: Cédric Sueur, Jean-Louis Deneubourg, Odile Petit and Iain D. Couzin, Group size, grooming and fission in primates: A modeling approach based on group structure, Journal of Theoretical Biology, doi:10.1016/j.jtbi.2010.12.035

This is a PDF file of an unedited manuscript that has been accepted for publication. As a service to our customers we are providing this early version of the manuscript. The manuscript will undergo copyediting, typesetting, and review of the resulting galley proof before it is published in its final citable form. Please note that during the production process errors may be discovered which could affect the content, and all legal disclaimers that apply to the journal pertain. 


\section{Group size, grooming and fission in primates: a modeling approach based on group}

2 structure.

3

4 Cédric Sueur ${ }^{1,2,3}$, Jean-Louis Deneubourg ${ }^{1}$, Odile Petit ${ }^{2}$ and Iain D. Couzin ${ }^{3}$

5

$6 \quad{ }^{1}$ : Unit of social ecology, free university of Brussels, Brussels, Belgium

$7 \quad 2$ : Ethologie des Primates, Department of Ecology, Physiology and Ethology, IPHC CNRS-

8 UDS, Strasbourg, France

$9{ }^{3}$ : Department of Ecology and Evolutionary Biology, Princeton University, Princeton, U.S.A.

11 Corresponding author: Cédric Sueur cedric.sueur@c-strasbourg.fr, csueur@princeton.edu

12 Ethologie des Primates, DEPE, IPHC CNRS-UDS, 23, rue Becquerel 67087 Strasbourg

13 Cedex, France.

14

15 Abstract

In social animals, fission is a common mode of group proliferation and dispersion and may be

17 affected by genetic or other social factors. Sociality implies preserving relationships between

18 group members. An increase in group size and/or in competition for food within the group can

19 result in decrease certain social interactions between members, and the group may split

20 irreversibly as a consequence. One individual may try to maintain bonds with a maximum of

21 group members in order to keep group cohesion, i.e. proximity and stable relationships.

22 However, this strategy needs time and time is often limited. In addition, previous studies have

23 shown that whatever the group size, an individual interacts only with certain grooming

24 partners. There, we develop a computational model to assess how dynamics of group cohesion

25 are related to group size and to the structure of grooming relationships. Groups' sizes after 
26 simulated fission are compared to observed sizes of 40 groups of primates. Results showed

27 that the relationship between grooming time and group size is dependent on how each

28 individual attributes grooming time to its social partners, i.e. grooming a few number of

29 preferred partners or grooming equally or not all partners. The number of partners seemed to

30 be more important for the group cohesion than the grooming time itself. This structural

31 constraint has important consequences on group sociality, as it gives the possibility of

32 competition for grooming partners, attraction for high-ranking individuals as found in

33 primates' groups. It could however also have implications when considering the cognitive

34 capacities of primates.

35

36 Keywords social network, agent-based model, cohesion, time allocation, population structure,

37 ODD protocol 


\section{Introduction}

Animals have to balance costs and benefits to be in close proximity to conspecifics (Krause and Ruxton 2002). On one hand, living in groups may offer the advantage of a lower predation risk and better efficiency when seeking resources. On the other hand, as group size increases, individuals may experience more within-group competition for food and have higher health risks due to the possible spread of contagious diseases (Krause and Ruxton 2002). Living in group implies interacting frequently with other group members in order to maintain group cohesion (Lehmann et al. 2007). Group cohesion may be defined using three criteria: stability, coordination and proximity. When group size or within-group competition for food increases, disadvantages may outnumber the advantages of group living, (Chapman et al. 1995; Janson and Goldsmith 1995; Ron et al. 1994). As a consequence, group cohesion decreases and the group may split either temporarily (Kerth et al. 2006; Poppa-Lisseanu et al. 2008; Wittemyer et al. 2005) or irreversibly (Henzi et al. 1997a, b; Lehman et al. 2007). In social or pre-social animals, irreversible fission is a common mode of group proliferation and dispersion. From amoeba to primates, this process may be affected by genetic or social factors (Chepko-Sade and Sade 1979; Gompper et al. 1998; Lehman et al. 2007; Seppa et al. 2008; Mehdiabadi et al. 2009; Rangel et al. 2009). In primates, irreversible group fissions rarely occur (about every five/ten years) and separation of different sub-groups often takes several months to years (Chepko-Sade and Sade 1979; Okamoto and Matsumura 2001; Van Horn et al. 2007).

In primates, grooming is considered to be the most common behavior for the maintenance of close social bonds (Schino 2001). Previous studies have shown that when an individual regularly grooms a particular partner, it seems to be more tolerant with this partner and more likely to support it during a conflict (without suggesting causality). Likewise, the partner in question typically reciprocates with the same tolerance and support (Henzi and 
63 Barrett 1999; Dunbar et al. 2009). However, grooming needs time, and time is a limited

64 resource (Dunbar 1992b; Lehmann et al. 2007; Majolo et al. 2008; Pollard and Blumstein

65 2008; Dunbar et al. 2009). In addition to maintaining social relationships, individuals need to

66 rest, forage and move (Pollard and Blumstein 2008). As a consequence, grooming seldom

67 exceeds $15 \%$ of day-time activity for most social species (Dunbar 1991; Lehmann et al.

68 2007). Some authors have investigated how an individual manages to maintain its social

69 relationships when grooming time is limited but group size or within-group competition for

70 food has increased (Chapman et al. 1995; Dunbar 1992b; Janson and Goldsmith 1995;

71 Lehmann et al. 2007; Majolo et al. 2008; Pollard and Blumstein 2008; Ron et al. 1994).

72 Lehmann et al. (2007) have suggested that when group size and the number of available

73 partners increase, each individual will have to spend more time grooming until a certain group

74 size for which it is impossible to maintain relationships with all group members (Dunbar

75 1992a; Lehmann et al. 2007; Schino et al. 2009). In this case, group cohesion - social

76 proximity and stability - decreases and group members permanently split. This hypothesis

77 implies that an individual tries to develop and maintain bonds with every group member, or at

78 least, the most of conspecifics. However, other studies have shown that whatever the group

79 size, an individual mainly interacts only with certain grooming partners, and does so much

80 more than with other potential partners (Kudo \& Dunbar 2001; Lehmann \& Dunbar 2009).

81 Individuals can therefore be considered to have a relatively fixed number of grooming

82 partners. This is the case, for instance, in blue monkey (Cecopithecus mitis, Cords 2001),

83 savanna baboons (Papio ursinus, Silk et al. 1999), in chimpanzees (Pan troglodytes, Watts

84 2000a,b) and in several macaque species (Macaca sp., Berman et al. 2008; Lin et al. 2008;

85 Nakamichi and Shizawa 2003). In this case, an individual allocates its grooming time to its

86 preferred partners. Consequently, grooming time should not be dependent on group size as it

87 was found in Majolo et al. (2008). 
88

In this study, we wanted to investigate the dynamic of group cohesion - how group cohesion evolves, from stable groups to groups having a greater probability to fission - according to group size and group structure of grooming relationships. By inducing a variation in the group size and the distribution of grooming time in a stochastic agent-based model, we make predictions about the conditions in which a group will irreversibly split. Most of studies on the link between social structure, grooming and group size (Kudo \& Dunbar 2001, Lehmann \& Dunbar 2009, Lehman et al 2009) followed standard practices in social network analyses and used a criterion for distinguishing casual from meaningful relationships. Modelling permits, without using this arbitrary criterion for preferred relationships, the simulation of interactions between group members (Seyfarth, 1977; Bryson et al. 2007; Meunier et al. 2006; Sellers et al. 2007; Puga-Gonzalez et al., 2009) and also resulting sub-grouping patterns (i.e. how individuals are sub-grouped; Ramos-Fernandez et al. 2006). We attributed a specific grooming time given by each individual to each other conspecifics. We tested the following three different hypotheses for a range of group sizes (from 2 to 200 individuals). (1) An individual divides its grooming time equally among all other group members. (2) An individual does not divide its grooming time equally among all other group members (i.e. it maintains a social bond with all other group members but these bonds are different depending on the partner concerned). (3) An individual divides its grooming time among specific individuals (this number is fixed to (a) 5 and (b) 10 partners per individual, see methods for details). This social structure - grooming a specific number of partners - is suggested by several studies (Berman et al. 2008; Cords 2001; Lin et al. 2008; Nakamichi and Shizawa 2003; Silk et al. 1999, Watts 2000a,b). Once the social structure was established in the model, individuals made a decision between two states (representing the two potential sub-groups). If less than four individuals split from the main group at the simulation end, we considered the cohesion maintained (see previous works on fission: Lefebvre et al. 2003; Ron et al. 1994; 
113 Van Horn et al. 2007). Then, we observed whether, and if so, how the group divided

114 according to its social structure. According to general rules of cohesion or of mimetism (the

115 probability to do a behavior depends on the number of individuals performing this behavior),

116 we expected that if all individuals are linked together, especially by equivalent grooming

117 relationships (hypothesis 1 ), the system would lead to amplification process - the more

118 individuals join a group, and the more other ones will join it - and no splitting would be

119 observed (Amé et al. 2006; Dussutour et al. 2005; Nicolis et al. 2003, Meunier et al. 2006).

120 Then, group cohesion would be influenced by grooming time and group size when grooming

121 relationships are not equal and especially when grooming is only given to a small number of

122 partners. The simulated data were compared to observed data in order to assess which model

123 most closely corresponds to the observed distribution of group sizes in primates (Lehmann et

124 al. 2007). This comparison allowed us to understand which is the best rule affecting group

125 structure and then population structure. We also tested how increased within-group

126 competition - leading to grooming time decrease by a foraging time increase - influences

127 group cohesion, and whether changes in group cohesion are similar according to group size.

128 We eventually used a path analysis to investigate the relationships (direct and/or indirect)

129 between group size, group structure and group cohesion.

131 2. Material and Methods

$132 \underline{2.1 \text { Data }}$

133 2.1.1. Empirical data: We used published data about group size and grooming time in order to

134 compare them to our simulation data. Data is taken from 40 published studies on Old World

135 primate species/populations (see Lehman et al., 2007 for details) and are summarized in table 1361. 
2.1.2. Theoretical data: We created theoretical networks using UCINET 6.0 (Borgatti et al.

138 2002). Groups contained 2 - 200 individuals $(2,5,10,20,40,60 \ldots 200)$. We set networks as

139 random (Erdos-Renyi random graph, with a linear distribution of links). The social structure is

140 different for each generated random network. We did not set networks as scale-free since

141 recent primate studies showed that social networks were not scale-free (i.e. with a power

142 distribution of links) but random (see Flack et al. 2006; MacCowan et al. 2008; Sueur and

143 Petit 2008; Kasper and Voelk1, 2009; Ramos-Fernandez et al. 2009; for studies on primate

144 social networks; see Wasserman and Faust 1994 for social network theory). We can observe

145 on fig.1 that some individuals are only groomed by one partner whilst other ones are groomed

146 by 7 or 8 partners, even if one individual can only groom 5 partners. Then, some social

147 characteristics such as dominance of individuals may be taken into account by considering the

148 network having an Erdos-Renyi random structure. For instance, individuals groomed by a lot

149 of partners on fig. 1 might be high-ranking individuals or matriarchs. Indeed, it was shown that

150 these individuals are more groomed than other ones (Nakamichi and Shizawa 2003; Schino

151 2001; Silk et al. 1999).

152

\subsection{Definitions of parameters}

154 We defined a bond (or a link) in a network as the time one individual groomed another one.

155 Then the relationship is directed and does not need to be reciprocal The grooming time per

156 individual $T(G)_{i}$ was defined as the time an individual spends grooming, whatever the number

157 of groomed partners $n$. According to observed data (see table 1) in this study, we considered

158 grooming to represent no more than $15 \%$ of total day-time activity.

159 For hypothesis 1 (an individual equally grooms all group members) and hypothesis 2 (an

160 individual non-equally/randomly grooms all group members), the mean strength of social

161 relationships (i.e. dyad's social bonds) was equal to the grooming time divided by the number 
162 of group members. For hypothesis 1 , all grooming time is equal to $T(G)_{i} / n$. For hypothesis 2 ,

163 minimum and maximum of grooming time are respectively $0.4 \%$ and $5.4 \%$ in a group of 5

164 individuals and $0.01 \%$ and $0.7 \%$ in a group of 200 individuals.

165 As far as hypothesis 3 is concerned (i.e. an individual grooms a fixed number of partners), we

166 carried out simulations with two preferred numbers of groomed partners, $n_{1}=5$ and $n_{2}=10$.

167 These correspond to the average and to the maximum numbers, respectively, of groomed

168 partners found in experimental studies regardless of the group size or the species (Berman et

169 al. 2008; Cords 2001; Lin et al. 2008; Nakamichi and Shizawa 2003; Silk et al. 1999; Watts

170 2000a,b; Kudo \& Dunbar 2001; Lehmann \& Dunbar 2009). These studies revealed that the

171 time taken by an individual to groom a non-preferred group member could be considered

172 unimportant compared to the time taken to groom its preferred partners. Previous studies have

173 reported that even if individuals groomed a specific number of individuals, high-ranking

174 individuals or matriarchs can be groomed more than others (Nakamichi and Shizawa 2003;

175 Schino 2001; Silk et al. 1999). We took into account these results to build the theoretical

176 group structure. Even if the number of partners an individual grooms is fixed (to 5 and 10), an

177 individual can be groomed by more (or less) than 5 or 10 grooming partners (see fig. 1 for an

178 example).

179 In our model, we decided to simulate an increased within-group competition by reducing

180 grooming time in steps of $20 \%$ (i.e. $-20,-40,-60,-80,-100 \%$ ). We attributed the new social

181 bonds equally for hypothesis 1 and randomly for hypothesis 2 . For hypothesis 3, we deleted

182 one partner at each step (i.e. 4, 3, 2, 1 and 0 partner). Indeed, previous studies reported that

183 decreased grooming time seems to have differing affects on an individual's social bonds: in

184 the case of high within-group competition, social bonds were mainly observed amongst kin,

185 and an attraction was observed towards the highest-ranking individuals (Berman et al. 2008; 
Majolo et al. 2008; Schino 2001; Watts 2000a,b). We created the networks varying using

187 UCINET 6.0 (Borgatti et al. 2002; Krause et al. 2007; Wey et al. 2007).

188 Group fission was considered to have occurred when the group irreversibly split into two sub189 groups (i.e. daughter groups, Ron et al. 1994) containing more than three individuals each.

190 This criterion of three individuals was based on group fission studies (Dunbar 1988; Lefebvre 191 et al. 2003; Ron et al. 1994; Van Horn et al. 2007). It is suggested that if the number

192 individuals leaving the group is inferior to three individuals (as dispersing males, females 193 with juveniles), it is more considered as dispersion than fission.

194

\subsection{The model}

196 We described the model according to the ODD protocol (i.e. Overview, Design concepts and

197 Details; Grimm et al. 2006).

198 Purpose

199 The purpose of the model is to assess how group structure in terms of group size and

200 distribution of grooming between individuals (hypotheses 1 to 3) leads to group fission or 201 allow group cohesion (see 2.2 for definitions). In our model, each individual has to choose

202 between two sub-groups according to the social relationships it has with each individual in 203 each sub-group. Then, the global variable we observed - group fission or group cohesion - is 204 based on the sum of individual decisions.

205 State variables and scales

206 The model is based on rules of mimetism/cohesion (Markov chain process) described in 207 several studies on collective phenomena (Amé et al. 2006; Gautrais et al. 2007; Dussutour et 208 al. 2005). In this model, the probability of an individual joining a collective movement in one 209 direction (the future sub-group) depends on the number but also the strength of relationships it 210 has with the individuals already in this direction. The number of individuals, individual 
211 identities and the network of affiliative relationships of each theoretical social network are

212 included in the model. Then, an individual is only characterized by its affiliative relationships,

213 based on grooming time he gave and received from its conspecifics. This model was already

214 used in Sueur et al. (2010). In this study, authors explained how Tonkean and rhesus

215 macaques joined a sub-group during short-term fissions. For both species, the affiliative

216 relationships (i.e. the social network, based on contact between individuals) explain the sub-

217 grouping patterns. Even if individuals are all connected together (one individual was at least

218 observed once with each group member), strength of social relationships leads to fission. In

219 this study, it means that the group fission or cohesion will not only depend on the group size

220 but also on how individuals are connected (hypotheses 1 to 3 ).

221 Process overview and scheduling

222 Each group is characterized by its size (number of individuals per group) and its structure

223 (how individuals are connected). Individuals are characterized by their social relationships

224 depending on the three tested hypotheses and by a state $S$. At the start of a simulation all

225 group members are in state $s 0$ (i.e. group 0 , initial group). Then, all individuals will have to

226 choose between state $s 1$ (i.e. sub-group 1) and $S 2$ (i.e. sub-group 2) according to their own

227 social relationships. This process based on social network will lead to the group cohesion or

228 the group fission. This is the only measure we took into consideration at the end of a

229 simulation. Simulations stop when all group members have changed from state $s 0$ to states $s 1$

230 or $s 2$. Groomed partners for each group member were attributed randomly (see Data for

231 details). The model was then implemented in Netlogo 3.1.4 (Wilensky 1999). We set the

232 number of simulations to 10,000 for each hypothesis and for each set of tested parameters.

233 Design concepts

234 Emergence: the only phenomenon emerging from individual decisions in the model is the 235 group fission or cohesion. 
236 Fitness: we did not measure fitness of individuals in this study.

237 Interaction: individuals are linked to another one by the grooming time they give or they

238 receive (see 2.2 for details).

239 Sensing: to change state $S$ (1 or 2$)$, individuals take into account an intrinsic probability $\lambda_{i S}$

240 and the relationships they have with individuals already in the state $S$.

241 Stochasticity: the model is stochastic. At each time step, a number is randomly attributed to

242 each individual and this number will determine if individual will change of state and for

243 which state, according to the probabilities to be in each state.

244 Collectives: Collectives are represented as social groups of primates. Collectives occur as

245 phenomena emerging from individual behaviour, specifically from the way to choose one sub-

246 group (i.e. state) or another one according to the relationships an individual has in each

247 sug(group (i.e. each state). The collective phenomenon emerging from this choice is the group

248 fission (or the group cohesion).

249 Observation: We set the number of simulations to 10,000 for each hypothesis and for each set

250 of tested parameters (i.e. group size). Then, for each hypothesis and each group size, we

251 obtained a value of group cohesion (how much time the group staid cohesive up on the 10,000

252 simulations)

253 Initialization

254 At the start of a simulation all group members are in state $s 0$ (i.e. group 0 , initial group). We

255 then induce a change of state in two randomly chosen individuals: state $s$ (i.e. sub-group 1)

256 for one individual and state $s 2$ (i.e. sub-group 2) for the other. These two individuals are

257 therefore the basis of the formation of the two sub-groups.

258 Input 
259 At each time step, a number between 0 and 1 is randomly attributed to all other individuals $i$

260 in state $s 0$; when this number is lower than the theoretical probability $\psi_{i s_{1}}\left(\mathrm{P}_{1}=\left[0, \psi_{i s_{1}}\right]\right)$ the

261 individual changes from state $s 0$ to state $s 1$; when this number is comprised between $\psi_{i s_{1}}$ and

$\left.\left.262 \psi_{i s_{1}}+\psi_{i s 2}\left(\mathrm{P}_{2}=\right] \psi_{i s_{1}}, \psi_{i s 2}\right]\right)$, then the individual changes from state $s 0$ to state $s 2$; however,

263 no change of state occurs if this number is superior to $\left.\left.\psi_{i s_{1}}+\psi_{i s 2}\left(\mathrm{P}_{3}=\right] \psi_{i s 2}, 1\right]\right)$, with $\mathrm{P}_{1}+\mathrm{P}_{2}$

$264+\mathrm{P}_{3}=1$.

265 If $\Sigma r(k, i)=0$ for an individual $i$, it changed of state according to its intrinsic probability $\lambda$.

266 The probability $\psi_{i s}$ for an individual $i$ in state 0 to turn into state $s(1$ or 2$)$ was:

$267 \quad \psi_{i s}=\lambda_{i}+\left(\sum_{k=1}^{N-1} r(k, i)_{s}\right)^{p}$

268 where $\lambda_{i}$ was the intrinsic probability to change state. We considered that all group members

269 had the same intrinsic probability. $\lambda_{i}=0.0001$

$270 p$ determined the degree of non-linearity in the response shown by individual $i$. The higher the

271 value of $p$ was, the higher was the resulting discrimination between the both directions (i.e.

272 the higher the individual probability $\Psi$ to go into state $s$ ) was, suggesting a deterministic

273 response in this study (Amé et al. 2006; Dussutour et al. 2005; Nicolis et al. 2003). $p=5$

$274 \lambda_{i}$ and $p$ were chosen according to previous studies using similar models in primates (Meunier

275 et al. 2006; Petit et al. 2009; Sueur et al. 2009, 2010; Jacobs et al. in press)

$276 r(k, i)_{s}$ was the social bond of $i$ towards $k$ when individual $k$ was already in state $s$. If individual

$277 k$ was not yet in state $s$, then $r(k, i)_{s}=0$.

$278 \Sigma r(k, i)_{s}$ represented the sum of social bonds for individual $i$ in state $s$.

279 Submodels

280 Hypothesis 1: (an individual grooms all group members equally):

$281 \quad r(k, i)_{s}=\omega_{\mathrm{k}, \mathrm{i}} * \mathrm{~T}(\mathrm{G})_{\mathrm{i}}$ 
282 where $\omega_{k, i}$ is the weight (strength of social bonds) between individual $i$ and individual $k$ and

$283 \mathrm{~T}(\mathrm{G})_{\mathrm{i}}$ is the grooming time per individual.

284 For this hypothesis,

$285 \quad \forall t_{r} \omega_{k t}=1 / k_{N-1} \quad\left(\right.$ all $r(k, i)_{s}$ were equal).

$286 N$ is the number of individuals in the group.

$287 \mathrm{~T}(\mathrm{G})_{\mathrm{i}}=0.15$

288

289 Hypothesis 2 (an individual does not groom all group members equally):

$290 \mathrm{r}(\mathrm{k}, \mathrm{i})_{\mathrm{s}}=\omega_{\mathrm{k}, \mathrm{i}} \cdot \mathrm{T}(\mathrm{G})_{\mathrm{i}}$

291 with all $\omega_{k, i}$ were attributed randomly according to a normal distribution in order that $\omega_{k, i}>0$

292 and $\Sigma \omega_{k, i}=1$ for each individual of each group.

$293 \mathrm{~T}(\mathrm{G})_{\mathrm{i}}=0.15$

294 For this second hypothesis, an individual groomed all other group members but almost all the $295 r(k, i)_{s}$ were seen to be different (see Data for details).

297 Hypothesis 3 (an individual grooms a fixed number $\mathrm{n}$ of partners):

298

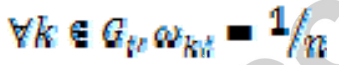

$\forall k \notin G_{t} \omega_{k t}=0$

299

300 where $n$ is the number of groomed partners (see Definitions of parameters for explanation)

301 and $G_{i}$ the group of $G$ partners groomed by the individual $i$.

302

$303 \quad 2.4$ Group structure analyses 
304 Group structure was analyzed using the social networking approach (Krause et al. 2007;

305 Wasserman and Faust 1994; Wey et al. 2008; Whitehead 2009). We used two indexes to

306 determine a group structure.

307 Group density: number of observed bonds divided by the number of possible bonds in the

308 group.

309 Group mean path length: an average number of all paths (shortest number of connections

310 between two individuals) between all pairs of individuals in the group. For the same density

311 (i.e. same number of social bonds in a group), group mean path length can be different. This

312 depends on how individuals are connected (see Wasserman and Faust 1994 for details on

313 social network theory; see Flack et al. 2006; MacCowan et al. 2008; Sueur and Petit 2008;

314 Kasper and Voelkl, 2009; Ramos-Fernandez et al. 2009; for studies on primate social

315 networks).

316 We calculated these indices using UCINET 6.0 (Borgatti et al., 2002).

317

$318 \quad 2.5$ Statistical analyses

319 The relationship between group size and group structure i.e. group mean path length and

320 density, was determined for the three hypotheses. Curve estimation tests were used to assess

321 whether the density and the group mean path length of a given group depends on group size,

322 and to establish the relationship between these variables (linear, logarithmic, and exponential)

323 (Newman et al. 2006). The same curve estimation tests were used to assess the dynamics of

324 group cohesion for each hypothesis according to group size. In order to understand the

325 relations between group cohesion and group size, we finally verified for each hypothesis how

326 group cohesion is affected by group density and group mean path length.

327 Distributions of group sizes after simulations were compared to observed distributions (data

328 from 40 studied groups, see Data for details) using the Kolmogorov-Smirnov test with 
Monte-Carlo significance estimation (the number of simulations for this test was set at

330 10,000). This allows to assess if simulated dynamics of group cohesion/fission fits with global

331 patterns observed in the wild. The theoretical values were obtained by dividing the number of

332 cohesive groups (i.e. that have not split) in each group size by the total number of cohesive

333 groups.

334 A Mann Whitney test was used to assess how increased within-group competition - a

335 decrease in the grooming time - influences group cohesion within our model. The initial

336 condition - $15 \%$ of grooming time - was compared to each other condition $(12,9,6,3$ and

337 0\%). Analyses were performed using SPSS 10 (SPSS Inc., Chicago, USA).

338 Path analysis was used to assess direct and indirect effects between group size, group

339 structure and group cohesion. Path analyses and diagrams were carried out using AMOS5

340 software (AMOS Development Corporation, Spring House, PA, U.S.A.) with maximum

341 likelihood estimations (for non-parametric analyses). This analysis was the most suitable for

342 obtaining the best model of possible relationships and causal effects between variables

343 (identified using AIC -Akaike Information Criterion - values, a measure a goodness of fit of

344 a model).

$345 \alpha$ was set at 0.05 . Means were $\pm \mathrm{SE}$ (standard error). Tests are two-tailed.

347 3. Results

$348 \quad 3.1$. Dynamics of group cohesion according to group size

349 3.1.1. Relationship between group structure and group size.

350 Group mean path length. For both hypotheses 1 (an individual grooms all other group

351 members equally) and 2 (an individual does not groom all other group members equally), the

352 group mean path length was constant (1.00) whatever the group size (fig.2a). For hypothesis 3

353 (an individual grooms a fixed number of partners), the best fit equation between the group 
354 mean path length and the group size was logarithmic, whatever the number of groomed

355 partners ( 5 or 10$)\left(\mathrm{N}=13\right.$ tests group sizes, $\mathrm{F}_{1,11} \geq 195.945, \mathrm{R}^{2} \geq 0.947, \mathrm{P}<0.000001$; fig.2a),

356 showing that path length and, thus connectivity between individuals highly vary for small

357 group size (until about 40 individuals per group) whilst it is more constant for large group

358 sizes.

359 Group density. For hypotheses 1 and 2, the density was constant (1.00) whatever the group

360 size (fig.2b). For hypothesis 3 , the best fit equation between the group mean path length and

361 the group size was logarithmic, whatever the number of groomed partners $(5$ or 10$),(\mathrm{N}=13$,

$362 \quad \mathrm{~F}_{1,11} \geq 96.611, \mathrm{R}^{2} \geq 0.898, \mathrm{P}<0.000001 ;$ fig.2b).

363

364 3.1.2. Relationship between group cohesion and group size.

365 For hypothesis 1, group cohesion (defined as the ratio of the number of cases where "one of

366 the sub-groups containing three individuals or less" divided by the total number of

367 simulations) was a constant (1.00; fig.2c). For hypothesis 2 , the best fit equation between

368 group cohesion and group size was logarithmic $\left(\mathrm{N}=13, \mathrm{~F}_{1,11}=24.255, \mathrm{R}^{2}=0.68, \mathrm{P}=0.0004\right.$;

369 fig.2c). The decrease in group cohesion was only seen to be $0.085 \pm 0.004 \%$ in groups of 10 to

370200 members. For hypothesis 3, whatever the number of groomed partners (5 or 10), the best

371 fit equation between the group cohesion and the group size was exponential $\left(\mathrm{N}=13, \mathrm{~F}_{1,11} \geq\right.$

$372327.615, \mathrm{R}^{2} \geq 0.967, \mathrm{P}<0.000001$; fig.2c).

373 These results suggest that when an individual has social bonds with all other group members,

374 whatever the quality of these social bonds, group size has little influence on group cohesion

375 and consequently on group fission probability.

376

377

3.1.3. Relationship between group cohesion and group structure. 
378 Group mean path length. For hypotheses 1 and 2, group cohesion was constant (1.00)

379 whatever the group mean path length. For hypothesis 3, the best fit equation between mean

380 path length and group cohesion is negatively linear, whatever the number of groomed partners

$381 \quad(5$ or 10$)\left(\mathrm{N}=13, \mathrm{~F}_{1,11} \geq 219.38, \mathrm{R}^{2} \geq 0.952, \mathrm{P}<0.000001\right)$.

382 Group density. For hypotheses 1 and 2, the group cohesion was constant (1.00) whatever the

383 density. For hypothesis 3, the best fit equation between density and group cohesion is

384 logarithmic, whatever the number of groomed partners $(5$ or 10$)\left(\mathrm{N}=13, \mathrm{~F}_{1,11} \geq 471.13, \mathrm{R}^{2} \geq\right.$

$3850.977, \mathrm{P}<0.000001)$.

386 The equation best describing the relationship between density (and the group mean path

387 length) and group cohesion for 5 partners was similar to that calculated for 10 partners (table

388 2). These results suggest that group size seems to not directly influence group cohesion, but it

389 seems to indirectly do it through group structure, and only in the case of hypothesis 3.

390 However, this hypothesis needs to be statistically tested a test allowing to describe direct and 391 indirect effects of variables (see. 3.2 in Results).

392

393 3.1.4. Comparison of observed group distribution and simulated group distributions.

394 For the observed data, and for each hypothesis, we calculated the relative distribution of

395 group sizes. The best fit equation for the observed distribution was logarithmic $\left(\mathrm{N}=6, \mathrm{~F}_{1,4}=\right.$

$39621.29, \mathrm{R}^{2}=0.852, \mathrm{P}=0.008$; fig.3). For hypotheses 1 and 2, there was no relationship

397 between relative frequency and group size $\left(\mathrm{N}=11, \mathrm{~F}_{1,9} \leq 1.74, \mathrm{R}^{2} \leq 0.16, \mathrm{P} \geq 0.215\right.$; fig.3).

398 Their distributions significantly differed from the observed distribution $\left(\mathrm{N}_{\text {observed }}=6, \mathrm{~N}_{\text {simulated }}\right.$

$399=11, \mathrm{z}=1.314, \mathrm{P} \leq 0.021)$. For hypothesis 3 , whatever the number of groomed partners $(5$ or

400 10), the best fit was logarithmic $\left(\mathrm{N}=11, \mathrm{~F}_{1,9} \geq 720.55, \mathrm{R}^{2} \geq 0.98, \mathrm{P}<0.000001\right.$; fig.3). For 5

401 and 10 partners, the simulated distribution did not significantly differ from the observed

402 distribution $\left(\mathrm{N}_{\text {observed }}=6, \mathrm{~N}_{\text {simulated }}=11, \mathrm{z}=0.806, \mathrm{P}=0.356\right.$ for 5 partners; $\mathrm{N}_{\text {observed }}=6$, 
$403 \mathrm{~N}_{\text {simulated }}=11, \mathrm{z}=1.134, \mathrm{P}=0.086$ for 10 partners; fig. 3 ). However, $\mathrm{P}$ - values suggested that

404 there was less difference between the observed distribution and the distribution for 5 partners

405 than for 10 partners. The " 5 partners" condition seemed the best model to explain how an

406 individual attributed grooming time to group-mates.

407

408 3.2. How does an increase of within-group competition affect group cohesion?

409 When within-group food competition increased, group members had to spend more time

410 foraging (and therefore to move from one patch to another). As a consequence, grooming time

411 decreased (Berman et al. 2008; Lehmann et al. 2007; Sterck et al. 1997). For hypotheses 1

412 and 2, a decrease in grooming time did not affect group cohesion, whatever the group size

413 (Mann-Whitney test: $\mathrm{U} \geq 68.5, \mathrm{P} \geq 0.418$; see table 3 for means), except when grooming time

414 is null (Mann-Whitney test: $\mathrm{U}<0.001, \mathrm{P}<0.00001$, table 3). For hypothesis 3, a decrease in

415 grooming time (represented by a decrease in the number of partners) from $40 \%$ (3 partners) to

$416100 \%$ (0 partner), influenced group cohesion (Mann-Whitney test: $\mathrm{U} \leq 46, \mathrm{P} \leq 0.048)$. This

417 effect followed an exponential law $\left(\mathrm{N}=13, \mathrm{~F}_{1,11} \geq 31, \mathrm{R}^{2} \geq 0.74, \mathrm{P} \leq 0.0001\right)$. We can

418 therefore conclude that according to group size, group cohesion was affected non linearly by

419 decreased grooming time and a decreased number of partners.

420

$421 \quad 3.3$. Causal relations between group size, grooming time, group structure and group cohesion

422 The most likely causal relations among the different variables previously tested were assessed

423 using path analyses. For hypotheses 1 and 2, the most parsimonious causal model showed that

424 grooming time and group size did not affect group cohesion either directly or indirectly (AIC

$425=18 ; \mathrm{df}=2 ; \mathrm{P}=1$; fig.4a). These results confirmed what we expected below. In the case of

426 hypothesis 3, grooming time and group size affected group cohesion but did so indirectly 
427 through the group structure and especially through the group mean path length $(\mathrm{AIC}=38$; df $428=2 ; \mathrm{P}=0.021 ;$ see fig. $4 \mathrm{~b}$ for details about different influences).

429

430

\section{Discussion}

Time is a finite resource and grooming time therefore has to be limited if an individual also wishes to forage, rest or move (Dunbar 1992b; Lehmann et al. 2007; Majolo et al. 2008; Pollard and Blumstein 2008). Nevertheless, grooming is maybe the most important behavior used by primates for maintaining social relationships (Henzi and Barrett 1999; Schino 2001).

435 As a consequence, the time an individual attributes to grooming will likely influence the 436 quality and/or the quantity of its social bonds (Dunbar 1991, 1992b; Lehmann et al. 2007). If

437 the grooming time of an individual decreases, the quality and/or the quantity of its social 438 bonds should also decrease. Moreover, the structure of social networks - the number of partners per individual and the strength of these connections - may influence group fission

440 probability and therefore group size if the group splits (Koyama 2003; Van Horn et al. 2007).

441 As a consequence, grooming time should logically influence group cohesion and also thus

442 group size. Our study suggests that the relationship between grooming time, group size and 443 group cohesion depends on the way an individual distributes its grooming time to its specific 444 social partners. If an individual grooms all its conspecifics, in an equal way or not, group size 445 does not affect group structure and then group cohesion. If grooming time is however 446 distributed to a specific number of partners, group structure and then group cohesion are 447 affected.

448 It has previously been shown that the time primates invest in grooming increases with 449 group size (Dunbar 1991). Nevertheless, Lehmann et al. (2007) suggested that when group 450 size increases, each individual should spend more time grooming until a certain group size 451 (about 40 individuals) for which individuals can not devote more time to maintain 
452 relationships with all group members (Dunbar 1992a; Lehmann et al. 2007; Schino et al.

453 2009). As a consequence, group cohesion decreases and the group splits (Henzi et al. 1997a,

454 b). This hypothesis implies that individuals should be expected to try to maintain social bonds

455 with (i.e. to groom) all, or at least most of, group members. Our results, by contrast, suggest

456 that if this assumption is applied (hypotheses 1 and 2 in our study), group cohesion is not

457 influenced by grooming time, even if time for this activity decreases when group size

458 increases. In the same way, within-group competition is not predicted to affect group cohesion

459 when an individual grooms all its partners, but does have an effect when an individual has a

460 specific number of partners which it grooms. This result may be explained by the fact that, as

461 all individuals were linked to each other in one way or another (whatever the quality/strength

462 of these social bonds), group cohesion was high and therefore the probability of the group

463 splitting was low. This result is not dependent on our model but directly influenced by social

464 network and sociality of individuals. For instance, Amé et al. (2006) showed that when

465 several shelters are proposed, cockroaches (Blatta germanica) always aggregate together in

466 only one shelter if this one is able to host all individuals. Even if fission is possible, the group

467 cohesion of individuals does not lead them to split. Sueur et al. (2010) also showed that in

468 macaques, the highest the group cohesion is (more contacts between individuals, less

469 clustered), the lowest the probability to split is. An alternative to grooming all other group

470 members is to groom a specific number of partners (hypothesis 3). Several authors have

471 shown that individuals do not groom all available partners but rather a fixed number of

472 individuals, whatever the group size (Silk et al., 1999; Cords, 2001; Nakamichi and Shizawa,

473 2002; Berman et al., 2008; Lin et al., 2008; Watts 2000a,v). Under this hypothesis and as

474 found in Majolo et al. (2008), the grooming time an individual devotes to another is not

475 directly dependent on group size. However, the study of Majolo et al. (2008) was the only one

476 to propose this indirect link before our study and this result needs to be checked. Our model 
477 suggests that group size, grooming time and group cohesion are linked when an individual

478 grooms only a specific number of partners. In this scenario, group cohesion decreases when

479 group size increases and/or grooming time decreases. Kudo \& Dunbar (2001) also showed

480 that structure of small and large groups differ. Indeed, large groups seem to be more sub-

481 structured. This sub-grouping might be because animals deliberately invest their grooming in

482 core coalition partners (Kudo \& Dunbar 2001; Lehmann \& Dunbar 2009). Indeed, a

483 theoretical study on social network graphs showed a similar decrease of connectivity

484 according to nodes' number (Wu, 2005). Moreover, we showed that this relationship between

485 group cohesion and group size is logarithmic: when group size exceeded 40 individuals,

486 group cohesion was almost null. This link was however indirect: as (1) group size and

487 grooming time directly influenced group structure, and (2) group structure directly influenced

488 group cohesion (in our study the inverse probability that a group splits in two sub-groups),

489 therefore (3) group size and grooming time influenced group cohesion. To confirm this result

490 and to understand how the group structure evolved according to both group size and the

491 number of groomed partners, it would be interesting to study groups at the same size but with

492 a different number of partners per individual.

493 Moreover, Lehmann et al. (2007) showed for instance that female dispersion and sex

494 ratio influenced grooming: species with female philopatry spend more time grooming than

495 species with female dispersal. Even if social characteristics such as philopatric sex or the sex

496 ratio, that represent the variability of a social structure, are already included in the different

497 random networks we tested with our model, we did not identify them. However, it would be

498 interesting to assess how these characteristics influence the social network and then the group

499 cohesion.

$500 \quad$ The distribution of the number of groups staying cohesive according to group size was

501 similar, in our model with a fixed number of five partners, to that based on observed data. 
502 Previous studies have confirmed that, on average, an individual preferentially grooms five

503 partners (Berman et al. 2008; Cords 2001; Lin et al. 2008; Nakamichi and Shizawa 2003; Silk

504 et al. 1999; Watts 2000a,b), giving further support for our hypotheses. Even if an individual

505 grooms five preferred partners, it can still be groomed by more or less individuals than five

506 congeners itself, since grooming is not necessarily reciprocal (Kapsalis and Berman 1994a, b;

507 Nakamichi and Shizawa 2002; Schino 2001; Silk et al. 1999). This pattern has important

508 consequences on group sociality: it allows competition for grooming partners, attraction to

509 high-ranking individuals (Schino 2001) and may allow the emergence of phenomena such as

510 the biological market (i.e., exchanges of commodities according to supply and demand;

511 Fruteau et al. 2009). On the other hand, if an individual grooms all its partners, this kind of

512 competition for partners could not emerge. Kinship may also constrain the relationships of

513 individuals: they will groom their relatives. In these conditions, the two new sub-groups will

514 be more composed on kin related individuals (Chepko-Sade and Sade, 1979; Van Horn et al.,

515 2007). This influence did not affect however our results since groups having an influence of

516 kinship can also be represented using random networks as the ones we used in this study

517 (Flack et al. 2006; MacCowan et al. 2008; Sueur and Petit 2008; Kasper and Voelk1, 2009;

518 Ramos-Fernandez et al. 2009). Grooming a specific and low number of partners could also be

519 of interest when managing time (individuals do not need to change their grooming time when

520 group size increases) but could also have implications when considering cognitive capacities.

521 Several authors (Dunbar 1992a, 1996; Lehmann et al. 2007; Stevens et al. 2005) have

522 suggested that there is a relationship between the cognitive capacities (measured as the

523 neocortex ratio) and the number of relationships an individual can keep track of.

524 Remembering the grooming relationships for five partners would be the easiest solution for an

525 individual, and would be a more parsimonious process than having to remember its ties with

526 all group members. Moreover, grooming five partners rather than all group members may 
527 favor sub-grouping patterns and reduce within-group conflict by regrouping individuals with

528 similar social/physiological affinities (Aureli and Schaffner 2007; Couzin and Laidre, 2009;

529 Ramos-Fernandez et al. 2006).

530 We believe that a relationship may exist between group size and grooming time but

531 that this relationship would probably be indirect: an increase in group size could result in

532 more food competition between group members (Majolo et al. 2008). As a consequence, an

533 individual would have to increase its foraging time and therefore decrease its grooming time.

534 The consequence is not due to a higher number of partners, but to lower food availability. We

535 did not directly test the relation between food competition and group size in our model, but

536 several studies have already supported this hypothesis (Berman et al. 2008; Dittus 1988;

537 Dunbar 1992). Moreover, group size and grooming time, elements that can be influenced by

538 ecological factors such as food competition or predation (Lehmann et al. 2007; Majolo et al.

539 2008; Pollard and Blumstein 2008), did not directly influence the probability that a group

540 would split. Social relationships directly influenced group fission probability. And these

541 social relationships are resultants of the combined influence of group size and food

542 competition, but also of other factors as internal or structural constraints (Thierry et al. 2004).

543 This study was based on grooming interactions but we suggested that similar results

544 may be obtained for any positive interaction such as proximities, contacts or frequency of

545 lips-making for instance. Even if our model did not test all factors having a potential influence

546 on the structure of social relationships, it does show that the key characteristic of group

547 cohesion and stability is group structure (Wey et al. 2007). It is interesting to note that the

548 probability to find large group sizes decreases exponentially with group size in the context of

549 stable groups after irreversible fission but also in fission-fusion populations (Couzin \& Laidre

550 2009). We do not think that a group splits irreversibly in one event as it does in our model.

551 This irreversible fission might be long, from several months to several years (Chepko-Sade 
552 and Sade 1979; Okamoto and Matsumura 2001; Van Horn et al. 2007). We still lack of data

553 about dynamic of fission. It should be interesting to conduct more studies about dynamical

554 processes allowing a group to split. General principles seem to underlie rules of group

555 cohesion at different time scales. All factors, whether social or ecological, seem to influence

556 group cohesion through its structure. In the end, group fission probability may not depend on

557 the sum of individual decision-making based on physiological states and/or on their complex

558 interactions (Schino 2001; Tomasello and Call 1997), but may simply depend on the

559 properties of the social structure, as observed in several self-organized systems (Camazine et

560 al. 2001; Couzin and Krause 2003).

561

\section{Acknowledgements}

563 We are grateful to J. Munro for language editing and N. Poulain, biostatistician at the DEPE,

564 IPHC, for his help on analyses. This work was supported by Wallonia Brussels International,

565 the Belgian National Funds for Scientific Research, the Franco-American Commission, the

566 Alsace Region and the Fyssen Foundation.

567

\section{References}

569 Amé JM, Halloy J, Rivault C, Detrain C, Deneubourg JL (2006) Collegial decision making

570 based on social amplification leads to optimal group formation. Proc Nat Acad Sci U.S.A.

$571 \quad 103: 5835-5840$.

572 Aureli F, Schaffner CM (2007) Aggression and conflict management at fusion in spider

573 monkeys. Biol Lett. 3: 147-149.

574 Baldellou M, Adan A (1997) Time, gender, and seasonality in vervet activity: a

575 chronobiological approach. Primates. 38: 31-43. 
576 Baldellou M, Adan A (1998) Diurnal and seasonal variations in vervet monkeys' activity.

577 Psychol Rep. 83: 675-685.

578 Berman CM, Ogawa H, Ionica C, Yin H, Li J (2008) Variation in kin bias over time in a

579 group of Tibetan macaques at Huangshan, China: contest competition, time constraints or risk

580 response? Behaviour. 145: 863-896.

581 Bocian CM (1997) Niche seperation of black-and-white colobus monkeys (Colobus

582 angolensis and C. guereza) in the Ituri Forest. Ph.D. thesis, City University of New York.

583 Boesch C, Boesch-Achermann H (2000) The Chimpanzees of the Taï Forest: Behavioural

584 Ecology and Evolution. Oxford: Oxford University Press.

585 Borgatti SP, Everett MG, Freeman LC (2002) UCINET for Windows: Software for Social

586 Network Analysis. Harvard: Analytic technologies.

587 Bryson JJ, Yasushi A, Lehmann H (2007) Agent-based modelling as a scientific

588 methodology: a case study analyzing primate social behaviour. Phil Trans R Soc B. 362:

589 1685-1699. doi:10.1098/rstb.2007.2061

590 Butynski TM (1990) Comparative ecology of blue monkeys (Cercopithecus mitis) in high-

591 and low-density subpopulations. Ecol Monogr. 60: 1-26.

592 Buzzard PJ (2004) Interspecific Competition Among Cercopithecus campbelli, C. petaurista,

593 and C. diana at Taï Forest, Cote d'Ivoire. New York: Columbia University Press.

594 Chapman CA, Chapman LJ (2000) Constraints on group size in red colobus and red-tailed

595 guenons: examining the generality of the ecological constraints model. Int J Primatol. 21:

$596 \quad 565-585$.

597 Chapman CA, Wrangham RW, Chapman LJ (1995) Ecological constraints on group-size: an 598 analysis of spider monkey and chimpanzee subgroups. Behav Ecol Sociobiol. 36 : 59-70. 
599 Chepko-Sade BD, Sade DS (1979) Patterns of group splitting within matrilineal kinship

600 group: Study of social group structure in Macaca mulatta (Cercopithecidae, Primates). Behav

601 Ecol Sociobiol. 5: 67-86.

602 Clutton-Brock TH (1974) Activity patterns of red colobus (Colobus badius tephrosceles).

603 Folia Primatol. 21: 161-187.

604 Clutton-Brock TH (1975) Feedingbehaviour of redcolobusandblack and white colobus in East

605 Africa. Folia Primatol. 23: 165-207.

606 Cords M (1986) Interspecific and intraspecific variation in diet of 2 forest guenons,

607 Cercopithecus ascanius and C. mitis. J Anim Ecol. 55: 811-827.

608 Cords M (1995) Predator vigilance costs of allogrooming in wild blue monkeys. Behaviour.

609 132: 559-569.

610 Cords M (2001) Friendship among adult female blue monkeys (Cercopithecus mitis).

611 Behaviour. 139: 291-314.

612 Cords M (2002) Friendship among adult female blue monkeys (Cercopithecusmitis).

613 Behaviour. 139: 291-314.

614 Couzin ID, Krause J (2003) Self-organization and collective behaviours in vertebrates. Adv

615 Stud Anim Behav. 32: 1-75.

616 Couzin ID, Laidre ME (2009) Fission-fusion populations. Curr Biol. 19: R633-R635.

617 Dasilva GL (1989) The ecology of thewestern black and white colobus (Colobus polykomos

618 polykomos) on a riverine island in southeastern Sierra Leone. Ph.D. thesis, University of

619 Oxford.

620 Decker BS (1994) Effects ofhabitatdisturbance onthebehavioral ecology and demographics of

621 the Tana river red colobus (Colobus badius rufomitratus). Int J Primatol. 15: 703-737.

622 Davies G (1984) An ecological study of the red leaf monkey (Presbytis rubicund) in

623 dipterocarp forests of North Borneo. Ph.D. thesis, University of Cambridge. 
624 Dittus WP (1988) Group fission among wild toque macaques as a consequence of female

625 resource competition and environmental stress. Anim Behav. 36: 1626-1645.

626 Dunbar RIM (1974) Observations on the ecology and social organization of the green monkey

627 (Cercopithecus sabaeus.) in Senegal Primates. 15: 34-350.

628 Dunbar, RIM (1991) Functional significance of social grooming in primates. Folia Primatol.

$629 \quad 57: 121-131$.

630 Dunbar, RIM (1992a) Neocortex size as a constraint on group size in primates. J Hum Evol.

631 20: 469-493.

632 Dunbar RIM (1992b) Time: a hidden constraint on the behavioural ecology of baboons.

633 Behav Ecol Sociobiol. 31: 35-49.

634 Dunbar RIM (1996) Determinants of group size in primates: a general model. Proc Brit Acad. $63588: 33-57$.

636 Dunbar RIM, Dunbar EP (1974) Ecology and population dynamics of Colobus guereza in 637 Ethiopia. Folia Primatol. 21: 188-208.

638 Dussutour A, Deneubourg JL, Fourcassié V (2005) Amplification of preferences in a social 639 context: the case of wall-following in ants. Proc R Soc B. 272: 705-71.

640 Eley RM, Strum SC, Muchemi G, Reid GDF (1989) Nutrition, body condition, activity 641 patterns, and parasitism of free-ranging troops of Olive Baboons (Papio Anubis) in Kenya.

642 Am J Primatol. 18: 209-219.

643 Ellefson J (1974) A natural history of white-handed gibbons in the Malayan penninsula. In:

644 DM Rumbaugh. Eds., Gibbon and Siamang. Basel: Karger.

645 Fashing PJ (2001) Activity and ranging patterns of guerezas in the Kakamega Forest:

646 intergroup variation and implications for intragroup feeding competition. Int J Primatol. 22:

$647 \quad 549-577$. 
648 Fawcett KA (2000) Female relationships and food availability in a forest community of

649 chimpanzees. Ph.D. thesis, University of Edinburgh.

650 Flack JC, Girvan M, de Waal FBM, Krakauer DC (2006) Policing stabilizes construction of

651 social niches in Primates. Nature. 439: 426-429.

652 Fossey D, Harcourt AH (1977) Feeding ecology of free-ranging mountain gorilla. Gorilla

653 gorilla beringei. In: TH Clutton-Brock. Eds., Primate Ecology:Studies of Feeding and

654 Ranging Behaviour in Lemurs, Monkeys and Apes. pp. 415-44. New York: Academic Press.

655 Fruteau C, Voelkl B, van Damme E, Noë R (2009) Supply and demand determine the market

656 value of food providers in wild vervet monkeys. Proc Nat Acad Sci U.S.A. 106: 12007-12012.

657 Gautrais J, Michelena P, Sibbald A, Bon R, Deneubourg J (2007) Allelomimetic

658 synchronization in Merino sheep . Animal Behaviour 74 (5):1443-1454

659 Gittins P, Raemakers J (1980) Siamang, lar und agile gibbons. In: D. J. Chivers . Eds.,

660 Malayan Forest Primates: Ten Years' Study in Tropical Rain Forest. pp. 63-105. New York:

661 Plenum.

662 Gompper ME, Gittleman JL, Wayne RK (1998) Dispersal, philopatry and genetic relatedness

663 in a social carnivore: comparing males and females. Mol Ecol. 7: 15163.

664 Grimm V, Berger U, Bastiansen F, Eliassen S, Ginot V, Giske J, Goss-Custard J, Grand T,

665 Heinz SK, Huse G, Huth A, Jepsen JU, Jørgensen C, Mooij WM, Müller B, Pe'er G, Piou C,

666 Railsback SF, Robbins AM, Robbins MM, Rossmanith E, Rüger N, Strand E, Souissi S,

667 Stillman RA, Vabø R, Visser U, DeAngelis DL (2006) A standard protocol for describing

668 individual-based and agent-based models . Ecol Model 198 (1-2):115-126

669

670 Henzi SP, Lycett JE, Piper SE (1997a) Fission and troop size in a mountain baboon

671 population. Anim Behav. 53: 525-535. 
672 Henzi SP, Lycett JE, Weingrill T (1997b) Cohort size and the allocation of social effort by

673 female mountain baboons. Anim Behav. 54: 1235-1243.

674 Henzi SP, Barrett L (1999) The value of grooming to female primates. Primates. 40: 47-59.

675 Homewood K M (1976) Ecology and behaviour of the tana mangabey, Cercocebus galeritus

676 galeritus. Ph.D. thesis, University of London.

677 Howarth CJ, Wilson JM, Adamson AP, Wilson ME, Boase MJ (1986) Population ecology of

678 the ringtailed lemur, Lemur catta, and the white sifaka, Propithecus verreauxi, at Berenty,

679 Madagaskar. Folia Primatol. 47: 39-48.

680 Iwamoto T, Dunbar RIM (1983) Thermoregulation, habitat quality and the behavioural

681 ecology of gelada baboons. J Anim Ecol. 52: 357-366.

682 Jacobs A, Sueur C. Deneubourg JL \& Petit O (In press). Self-organization in primates: new

683 elements in brown lemurs. Int J Primatol

684 Janson CH, Goldsmith ML (1995). Predicting group size in primates: foraging costs and 685 predation risks. Behav Ecol Sociobiol. 36: 326-336.

686 Kaplin BA, Moermond TC (2000) Foraging ecology of the mountain monkey. Cercopithecus

687 l'hoesti.: implications for its evolutionary history and use of disturbed forest. Am J Primatol.

688 50: 227-246.

689 Kasper C, Voelkl B (2009) A social network analysis of primate groups. Primates. 50: 343690356.

691 Kerth G, Elbert C, Schmidtke C (2006) Group decision-making in fission-fusion societies:

692 evidence from two-field experiments in Bechstein's bats. Proc Roy Soc B. 273: 2785-2790.

693 Koyama NF (2003) Matrilineal cohesion and Social networks. Int J Primatol. 24: 797-811.

694 Krause J, Ruxton GD (2002) Living in Groups. Oxford: Oxford University Press.

695 Krause J, Croft DP, James R (2007) Social network theory in the behavioural sciences:

696 potential applications. Behav Ecol Sociobiol. 62: 15-27. 
697 Kudo H, Dunbar RIM (2001) Neocortex size and social network size in primates . Animal

698 Behaviour $62(4): 711-722$

699 Lawes MJ (1991) Diet of Samango monkeys. Cercopithecus mitis erythrarchus. in the Cape

$700 \quad$ Vidal Dune forest, South Africa. J Zool. 224: 149-173.

701 Lee PC (1981) Ecological and social influences on the development of vervet monkeys. Ph.D.

702 thesis, University of Cambridge.

703 Lefebvre D, Ménard N, Pierre JS (2003) Modelling the influence of demographic parameters

704 on group structure in social species with dispersal asymmetry and group fission. Behav Ecol

705 Sociobiol. 53: 402-410. \$

706 Lehman n J, Korstjens AH, Dunbar RI (2007) Grooming, group size and social cohesion in

707 primates. Anim Behav. 74: 1617-1629.

708 Lehmann J, Dunbar RIM (2009) Network cohesion, group size and neocortex size in female-

709 bonded Old World primates . Proc Roy Soc B 276 (1677):4417 -4422

710 Li ZY, Rogers E (2004) Habitat quality and activity budgets of white-headed langurs in Fusui,

711 China. Int J Primatol. 25: 41-54.

712 Lin TJ, AgoramoorthyG, Huang CC, Hsu MJ (2008) Effects of Troop Size on Social

713 Relations among Male Formosan Macaques, Macaca cyclopis. Zoologic stud. 47: 237-246.

714 Mackinnon J (1974) Behavior and ecology of wild orangutans (Pongo pygmaeus). Anim

715 Behav. 22: 3-74.

716 Majolo B, De Bortoli Vizioli A, Shino G (2008) Costs and benefits of group living in

717 primates : group size effects on behaviour and demography. Anim Behav. 76: 1235-1247.

718 doi:10.1016/j.anbehav.2008.06.008

719 Maruhashi T (1981) Activity patterns of a troop of Japanese monkeys (Macaca fuscata yakui)

720 on Yakushima Island, Japan. Primates. 22: 1-14. 
721 Matsumoto-Oda A, Oda R (1998) Changes in the activity budget of cycling female

722 chimpanzees. Am J Primatol. 46: 157-166.

723 McKey D, Waterman PG (1982) Ranging behaviour of a group of black colobus (Colobus

724 satanas) in the Douala-Edea Reserve, Cameroon. Folia Primatol. 39: 264-304.

725 McCowan B, Anderson K, Heagarty A, Cameron A (2008) Utility of social network analysis

726 for primate behavioral management and well-being. Appl Anim Behav Sci. 109: 396-405

727 Mehdiabadi NJ, Kronforst MR, Queller DC, Strassman JE (2009) Phylogeny, reproductive

728 isolation and kin recognition in the social amoeba dictyostelium purpureum. Evol. 63: 542-

729548.

730 Meunier H, Leca JB, Deneubourg JL, Petit O (2006) Group movement decisions in capuchin

731 monkeys: the utility of an experimental study and a mathematical model to explore the

732 relationship between individual and collective behaviours. Behaviour. 143: 1511-1527. doi:

$733 \quad 10.1163 / 156853906779366982$

734 Nagel U (1973) Comparison of anubis baboons, hamadryas baboons and their hybrids at a

735 species border in Ethiopia. Folia Primatol. 19: 104-165.

736 Nakamachi M, Shizawa Y (2003) Distribution of grooming among adult females in a large,

737 free-ranging group of Japanese macaques. Int J Primatol. 24: 607-625.

738 Newman M, Barabasi AL, Watts DJ (2006)The structure and dynamics of networks.

739 Princeton: Princeton University Press.

740 Nicolis SC, Detrain C, Demolin D, Deneubourg JL (2003) Optimality of collective choices: a

741 stochastic approach. Bull Math Biol. 65: 795-808.

742 Nishida T (1990) The Chimpanzees of the Mahale Mountains. Tokyo: University of Tokyo 743 Press. 
744 Oates JF (1977a) The guereza and its food. In: TH Clutton-Brock. Eds., Primate Ecology:

745 Studies of Feeding and Ranging Behaviour in Lemurs, Monkeys and Apes. pp. 275-321.

746 London: Academic Press.

747 Oates JF (1977b) The social life of a black-and-white colobus monkey, Colobus guereza. Zeit

748 Tierpsychol. 45: 1-60.

749 Pollard KA, Blumstein DT (2008) Time allocation and the evolution of group size. Anim

750 Behav. 76: 1683-1699

751 Pollock J (1977) The ecology and sociology of feeding in Indri indri. In: TH Cluttonbrock.

752 Eds., Primate Ecology. pp. 37-68. London:Academic Press.

753 Popa-Lisseanu AG, Bontadina F, Mora O, Ibanez C (2008) Highly structured fission-fusion

754 societies in an aerial-hawking carnivorous bat. Anim behav. 75: 471-482.

755 doi:10.1016/j.anbehav.2007.05.011

756 Puga-Gonzalez I, Hildenbradt H, Hemelrijk CK (2009) Emergent patterns of social affiliation

757 in primates, a model. Plos Comput Biol. 5, e10000630.

758 Okamoto K, Matsumura S (2001) Group fission in Moor macaques. Int J Primatol. 22: 481-

759493.

760 Ramos-Fernandez G, Boyer D, Gomez VP (2006) A complex social structure with fission-

761 fusion properties can emerge from a simple foraging model. Behav Ecol Sociobiol. 60: 536-

762549.

763 Ramos-Fernandez G, Boyer D, Aureli F, Vick LG (2009) Association networks in spider

764 monkeys. Ateles geoffroyi. Behav Ecol Sociobiol. 63: 999-1013.

765 Rangel J, Mattila HR, Seeley TD (2009) No intracolonial nepotism during colony fissioning

766 in honey bees. Proc Roy Soc B. 276: 3895-3900.

767 Ron T, Henzi SP, Motro U (1994) A new model of fission in primate troops. Anim Behav. 47:

$768 \quad 223-226$. 
769 Schino G (2001) Grooming, competition and social rank among female primates: a meta-

770 analysis. Anim Behav. 62, 265-271.

771 Schino G, Giuseppe F, Visalberghi E (2009) The Time Frame of Partner Choice in the

772 Grooming Reciprocation of Cebus apella. Ethology. 115: 70-76.

773 Sellers WI, Hill RA, Logan BS (2007) An agent-based model of group decision making in

774 baboons. Phil Trans R Soc B. 362: 1699-1710.

775 Seppa P, Fernandez-Escudero I, yllenstrand N, Pamilo P (2008) Colony fission affects kinship

776 in a social insect. Behav Ecol Sociobiol. 62: 589-597.

777 Seth PK, Seth S (1986). Ecology and behaviour of rhesus monkeys in India. In: JG Else, PC

778 Lee. Eds., Primate Ecology and Conservation. pp. 89-103. Cambridge: Cambridge University

779 Press.

780 Seyfarth RM (1977) A model of social grooming among adult female monkeys. J Theo Biol.

$781 \quad 65: 671-698$.

782 Silk JB, Sefarth RM, Cheney DL (1999) The structure of social relationships among female

783 savanna baboons in Moremi reserve, Botswana. Behaviour. 136: 679-703.

784 Son VD (2004) Time budgets of Macaca fascicularis in a Mangrove Forest, Vietnam. Lab

785 Primate Newslett. 43: 1-4.

786 Stanford CB (1998) Chimpanzee and Red Colobus: the Ecology of Predator and Prey.

787 Cambridge: Harvard University Press.

788 Starin ED (1991) Socioecology of the red colobus monkey in the Gambia with particular

789 reference to femaleemale differences and transfer patterns. Ph.D. thesis, City University of

790 New York, 406 pp.

791 Sterck EH., Watts DP, van Schaik CP (1997)The evolution of female social relationships in

792 nonhuman primates. BehavEcol Sociobiol. 41: 291-309. 
793 Stevens JR, Cushman FA, Hauser MD (2005) Evolving the psychological mechanisms for

794 cooperation. Ann Rev Ecol Evol Syst .36: 499-518.

795 Struhsaker TT (1979) Socioecology of five sympatric monkey species in the Kibale forest,

796 Uganda. Adv Stud Behav. 9: 159-228.

797 Struhsaker TT (1980) Comparison of the behaviour and ecology of red colobus and redtail

798 monkeys in the Kibale Forest, Uganda. Af J Ecol. 18: 33-51.

799 Struhsaker TT, Leland L (1979) Socioecology of five sympatric monkey species in the Kibale

$800 \quad$ Forest, Uganda. Adv Stud Behav. 9: 159228.

801 Sueur C, Petit O (2008) Organization of group members at departure of joint movements is

802 driven by social structure in macaques. Int J Primatol. 20: 1085-1098.

803 Sueur C, Petit O, Deneubourg J (2009) Selective mimetism at departure in collective 804 movements of Macaca tonkeana: an experimental and theoretical approach. Anim 805 Behav $78(5): 1087-1095$

806 Sueur C, Petit O, Deneubourg J (2010) Short-term group fission processes in macaques: a

807 social networking approach . J Exp Biol 213 (8):1338-1346

808 Sugiyama Y (1976) Characteristics of the ecology of the Himalayan langurs. J Hum Evol. 5:

809249277.

810 Sussmann RW (1977) Feeding behaviour of Lemur catta and Lemur fulvus. In: TH

811 Cluttonbrock. Eds. ,Primate Ecology. pp. 1-39. London: Academic Press.

812 Teas J, Richie T, Taylor H, Southwick CH (1980) Population patterns and behavioural

813 ecology or rhesus monkeys. Macaca mulatta. in Nepal In: DG Lindburg. Eds. The Macaques.

814 pp. 247-262. New York: Van Nostrand Reinhold.

815 Tomasello M, Call J (1997) Primate Cognition. New York: Oxford University Press.

816 Tutin CEG, McGrew WC, Baldwin PJ (1983) Social organization of savanna-dwelling

817 chimpanzees, Pan troglodytes verus, at Mt. Assirik, Senegal Primates 24: 154-173. 
818 Van Horn RC, Buchan JC, Altmann J, Alberts SC (2007) Divided destinies: group choice by

819 female savannah baboons during social group fission. Behav Ecol Sociobiol. 61: 1823-1837.

820 Van Noordwijk M A (1985) The Socioecology of Sumatran Longtailed Macaques. Macaca

821 fascicularis. II. The Behaviour of Individuals. Utrecht: University of Utrecht.

822 Wasserman S, Faust K (1994) Social network analysis. Cambridge: Cambridge University

823 Press.

824 Watts DP ( 2000a) Grooming between male chimpanzees at Ngogo, Kibale National Park. I.

825 Partner number and diversity and grooming reciprocity. Int J Primatol 21:189-210.

826 Watts DP (2000b) Grooming between male chimpanzees at Ngogo, Kibale National Park. II.

827 Influence of male rank on possible competition for partners Int J Primatol 21:211-238.

828 Wey T, Blumstein DT, Shen W, Jordan F (2007) Social network analysis of animal

829 behaviour: a promising tool for the study of sociality. Anim Behav. 75: 333-344.

830 White FJ (1992) Activity budgets, feeding behavior, and habitat use of pygmy chimpanzees at

831 Lomako, Zaire. Am J Primatol. 26: 215-223.

832 White FJ, Chapman CA (1994) Contrasting chimpanzees and bonobos: nearest neighbor

833 distances and choices. Folia Primatol. 63 181-191.

834 Whitehead H (2009) SOCPROG programs: analysing animal social structures. Behav Ecol

835 Sociobiol. 63: 765-778.

836 Whiten A (1980) The Kloss gibbon in Siberut rain forest. Ph.D. thesis,University of

837 Cambridge.

838 Whitesides GH (1989) Interspecific associations of Diana monkeys, Cercopithecus diana, in

839 Sierra Leone, West Africa: biological significance or chance? Anim Behav. 37: 760-776.

840 Wilensky U (1999) NetLogo. http://ccl.northwestern.edu/netlogo. Center for Connected

841 Learning and Computer-Based Modeling. Northwestern University, Evanston, IL. 
842 Wittemyer G, Douglas-Hamilton I, Getz WM (2005) The socioecology of elephants: analysis

843 of the processes creating multitiered social structures. Anim Behav. 69: 1357-1371.

844 Wu WC (2005) Algebraic connectivity of directed graphs. Linear and multilinear algebra. 53:

$845 \quad 203-223$.

846 Yamakoshi G (1998) Dietary responses to fruit scarcity of wild chimpanzees in Bossou,

847 Guinea: possible implications for ecological importance of tool use. Am J Physical Anthropol.

848 106: 283-295.

849 Yamakoshi G (2004) Food seasonality and socioecology in Pan: are West African

850 chimpanzees another bonobo? Af Stud Monogr. 25: 45-60.

851

\section{Table legends}

853 Table 1: Data (Genus, species, group size and grooming time) and references of data used in 854 this study.

\begin{tabular}{|c|c|c|c|c|}
\hline Genus & Species & Group & Grooming & Reference(s) \\
\hline Avahi & laniger & 2 & 2 & 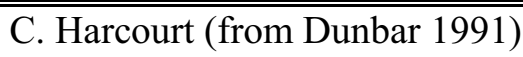 \\
\hline Cercocebus & galeritus & 27 & 5.5 & Homewood 1976 \\
\hline Cercopithecus & ascanius & 26.75 & 3.45 & Struhsaker 1980; Cords 1986 \\
\hline Cercopithecus & campbelli & 9 & 2.8 & Buzzard 2004 \\
\hline Cercopithecus & diana & 28.75 & 2.48 & Whitesides 1989; Buzzard 2004 \\
\hline \multirow[t]{4}{*}{ Cercopithecus } & mitis & 22.65 & 7.18 & Struhsaker and Leland 1979 \\
\hline & & & & Butynski 1990; Lawes 1991 \\
\hline & & & & Cords 1995, 2002 \\
\hline & & & & Kaplin and Moermond 2000 \\
\hline
\end{tabular}




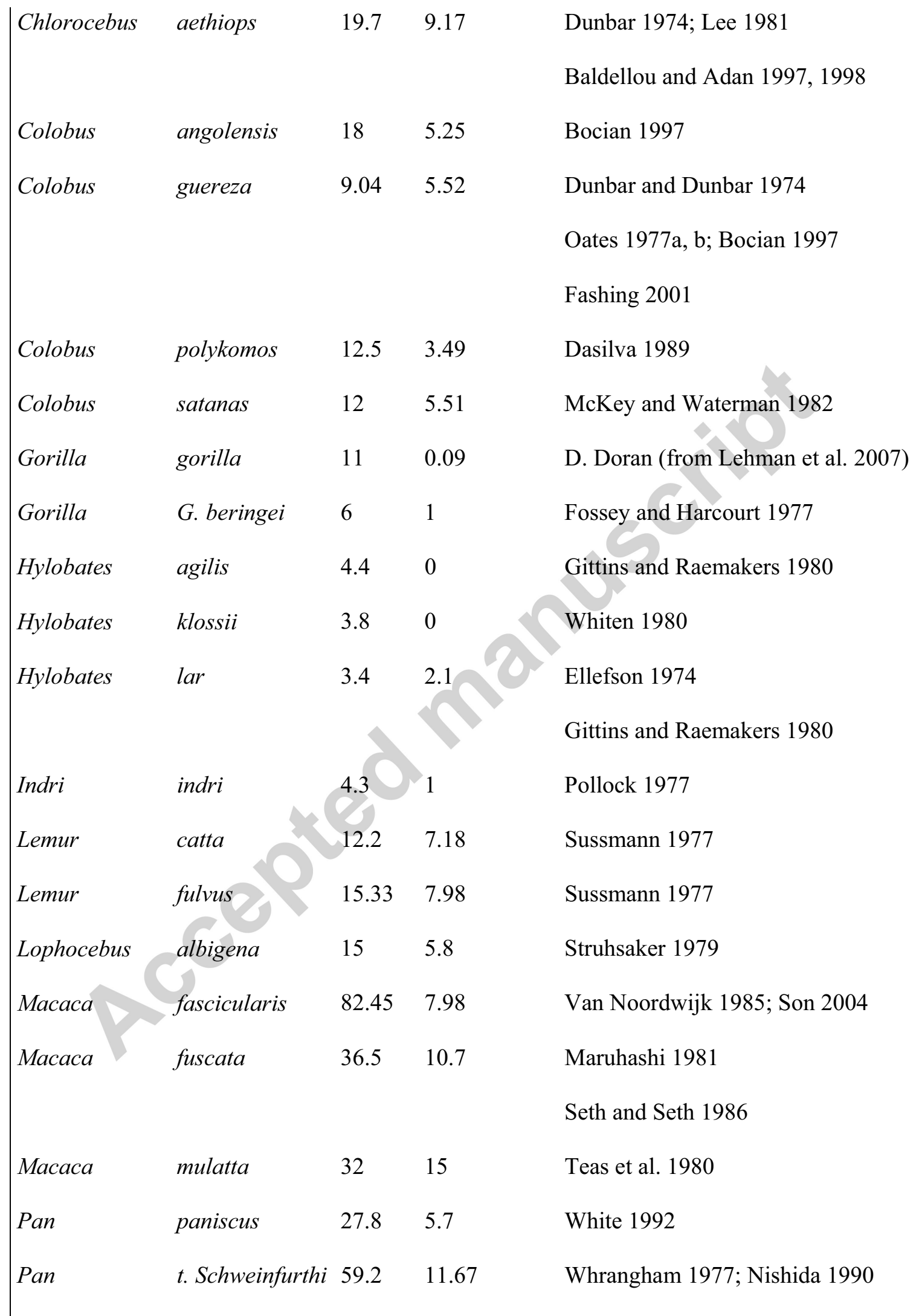




\begin{tabular}{|c|c|c|c|c|}
\hline & & & & White and Chapman 1994 \\
\hline & & & & Matsumoto-Oda and Oda 1998 \\
\hline & & & & Fawcett 2000 \\
\hline Pan & t. verus & 40.33 & 8.27 & Tutin et al. 1983 \\
\hline & & & & Yamakoshi 1998, 2004 \\
\hline & & & & Boesch and Boesch-Achermann 2000 \\
\hline Papio & anubis & 58.8 & 8.3 & Nagel 1973; Eley et al. 1989 \\
\hline Papio & ursinus & 28.07 & 12.64 & Henzi et al. $1997 \mathrm{~b}$ \\
\hline Papio & hamadryas & 51 & 13.5 & Nagel 1973 \\
\hline & & & & R. Noe and H. Korstjens (from Lehman et \\
\hline Piliocolobus & badius & 42.5 & 4.5 & al. 2007) \\
\hline Piliocolobus & rufomitratus & 16.16 & 0.83 & Decker 1994 \\
\hline Piliocolobus & temminckii & 26.2 & 5.4 & Starin 1991 \\
\hline Piliocolobus & tephrosceles & 51.67 & 4.99 & Clutton-brock 1974, 1975; Stanford 1998 \\
\hline & & & & Struhsaker and Leland 1979 \\
\hline & & & & Chapman and Chapman 2000 \\
\hline Pongo & pygmaeus & 1 & 0 & Mackinnon 1974 \\
\hline Presbytis & entellus & 33 & 4.4 & Sugiyama 1976 \\
\hline Presbytis & rubicunda & 7 & 0 & Davies 1984 \\
\hline & & & & R. Noe and H. Korstjens (from Lehman et \\
\hline Procolobus & verus & 3 & 3.58 & al. 2007) \\
\hline Propithecus & verreauxi & 5.1 & 4.7 & Howarth et al. 1986 \\
\hline Trachypithecus & leucocephalus & 10 & 11.71 & Li and Rogers 2004 \\
\hline Theropithecus & gelada & 144.7 & 17.4 & Iwamoto and Dunbar 1983 \\
\hline
\end{tabular}


856 Table 2: equations of relationship between mean path length and group cohesion and between

857 density and group cohesion, for 5 and 10 partners. Tests showed that the equations are similar

858 for 5 and 10 partners. We used a comparison test for two linear regressions (transformation

859 from logarithmic to linear for the relations between density and number of partners). We first

860 used a Snedecor test to compare variances of each distribution $\left(\mathrm{df}_{1}=\mathrm{df}_{2}=11, \mathrm{f} \leq 0.75\right)$. Then,

861 we tested if variable $\left(\mathrm{b} 1_{5 \text { partners }}-\mathrm{b} 1_{10 \text { partners }}, \mathrm{df}=22, \mathrm{~T} \leq 0.27\right)$ and variable $\left(\right.$ constant $_{5 \text { partners }}-$

862 constant $\left._{10 \text { partners }}, \mathrm{df}=22, \mathrm{~T} \leq 0.21\right)$ followed a Student law $(\mathrm{df}=22)$.

\section{Group cohesion}

\begin{tabular}{|c|c|c|c|c|c|c|}
\hline \multirow[t]{2}{*}{$\mathrm{N}=13$} & \multicolumn{2}{|l|}{5 partners } & \multicolumn{3}{|c|}{10 partners } & \multirow[t]{2}{*}{$\begin{array}{l}\text { similar } \\
\text { functions }\end{array}$} \\
\hline & function & constant $\mathrm{b} 1$ & function & cons & b1 & \\
\hline Group mean path length & linear & $1.51 \quad-0.45$ & linear & 1.48 & -0.42 & Yes $\quad \mathrm{P}<0.05$ \\
\hline Density & logarithmic & $1.03-0.23$ & logarithmic & 1.05 & 0.26 & Yes $\quad \mathrm{P}<0.05$ \\
\hline
\end{tabular}

863

864 Table 3: Influence of grooming time on mean group cohesion for each hypothesis

\begin{tabular}{lllll}
\hline grooming time & initial time & \multicolumn{2}{l}{ mean group cohesion } \\
\cline { 4 - 5 }$(\%$ per day time) & decrease $(\%)$ & hypothesis 1 & hypothesis 2 & hypothesis 3 \\
\hline \hline 15 (initial time) & -0 & 1.00 & 0.93 & 0.44 \\
12 & -20 & 1.00 & 0.93 & 0.33 \\
8 & -40 & 1.00 & 0.92 & 0.27 \\
6 & -60 & 1.00 & 0.93 & 0.22 \\
3 & -80 & 1.00 & 0.92 & 0.17 \\
0 & -100 & 0.00 & 0.00 & 0.00
\end{tabular}




\section{Figure captions}

867

868 Figure 1: Illustration of a social network with 40 individuals (squares). Number labels

869 indicated the number of group members that groomed a given individual (indegree, Faust and

870 Wasserman 1994). We showed from this graph that even if the number of partners groomed

871 by the same individual was fixed at 5 , an individual can be groomed by more (or less) than 5

872 grooming partners in the model. We built this network via Netdraw in UCINET 6.0 (Borgatti

873 et al. 2002). Distance between individuals represents the strength of associations, and was

874 calculated using multidimensional scaling (Whitehead 2009, Sueur and Petit 2008).

875

876 Figure 2: Influence of group size on group structure (a. on group mean path length and b. on

877 density) and on group cohesion (c.) for each hypothesis. For hypotheses 1 and 2, where an

878 individual groomed all other group members, there is no relationship between group size and

879 group structure, nor between group size and group cohesion, contrary to hypothesis 3 (where

880 an individual groomed a fixed number of partners).

881

882 Figure 3: Relative distribution of group size for observed data and under each hypothesis. The

883 curve line is the best-fit model explaining the distribution of observed data and corresponds to

884 an exponential law.

885

886 Figure 4: Path diagram indicating causal relations between group size, grooming time, group

887 structure, i.e. mean strength of social relationships (a.), number of partners (b.), density and

888 group mean path length, and group cohesion. Rectangles indicated observed variables.

889 Arrows indicated presumed causal relations: solid arrows represented the best model based on 
890 AIC value, using AMOS5; dotted arrows represented the relations we included in the analysis

891 but not selected in the best model. 


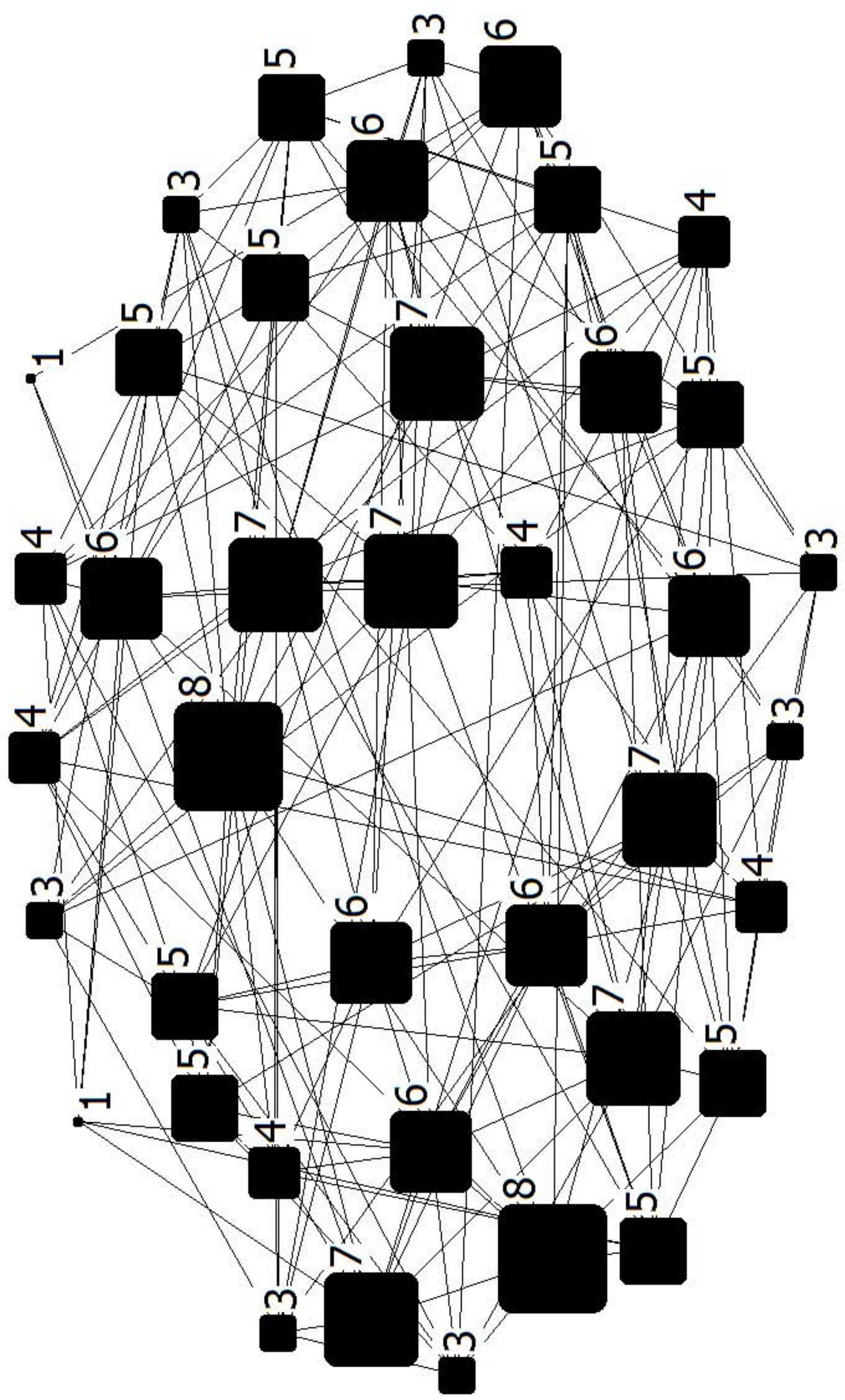



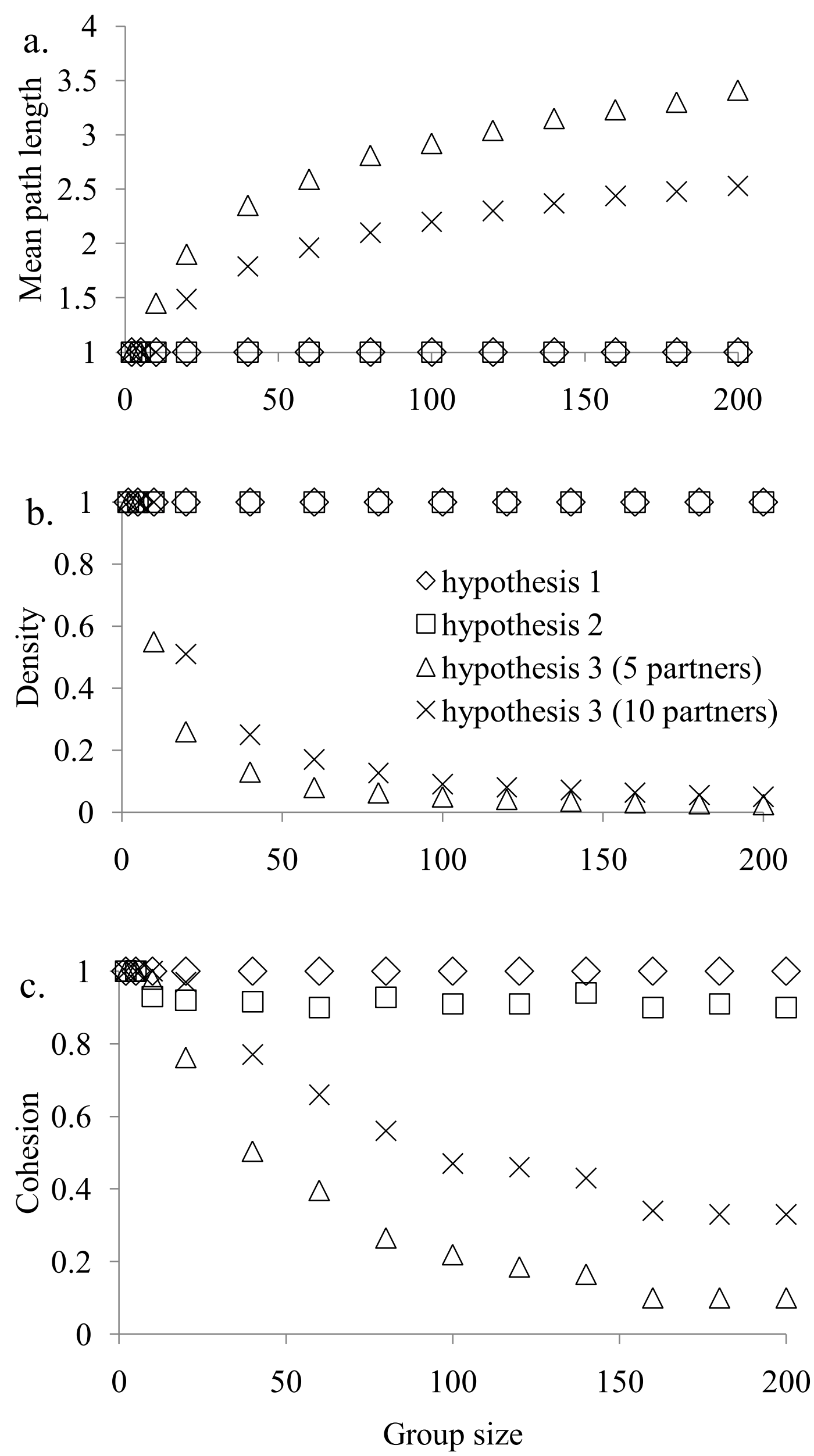


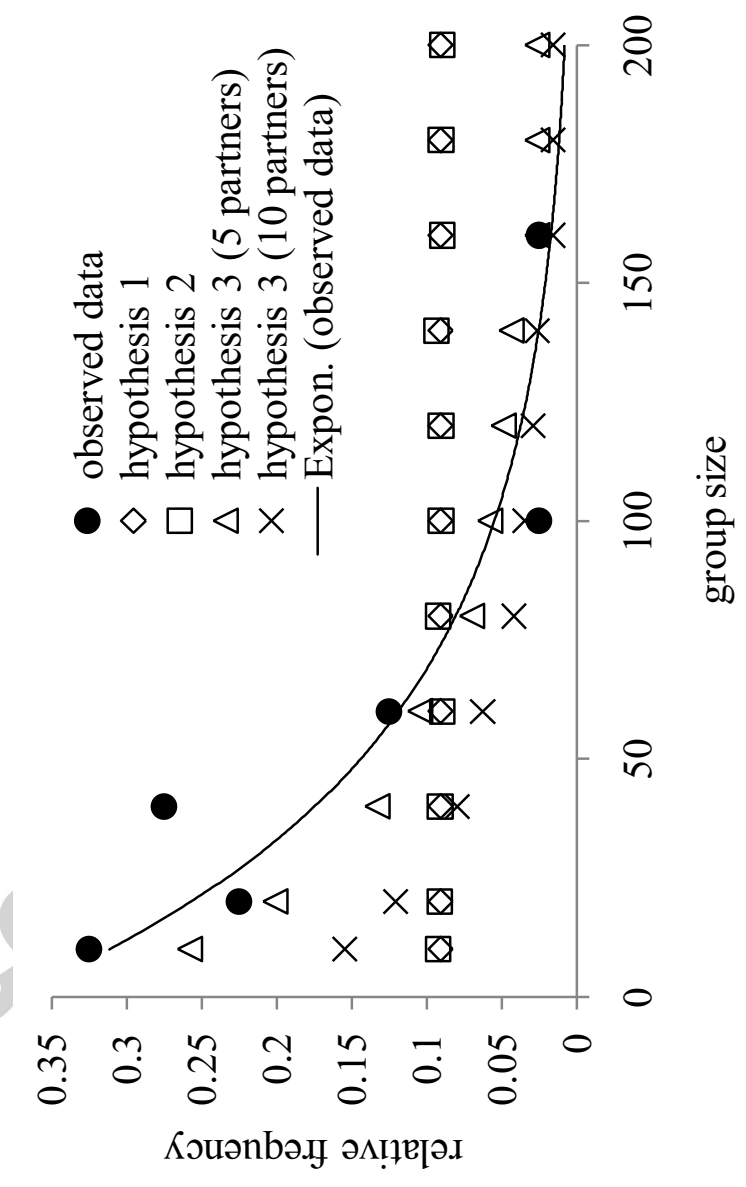




\section{a. Hypotheses 1 and 2}

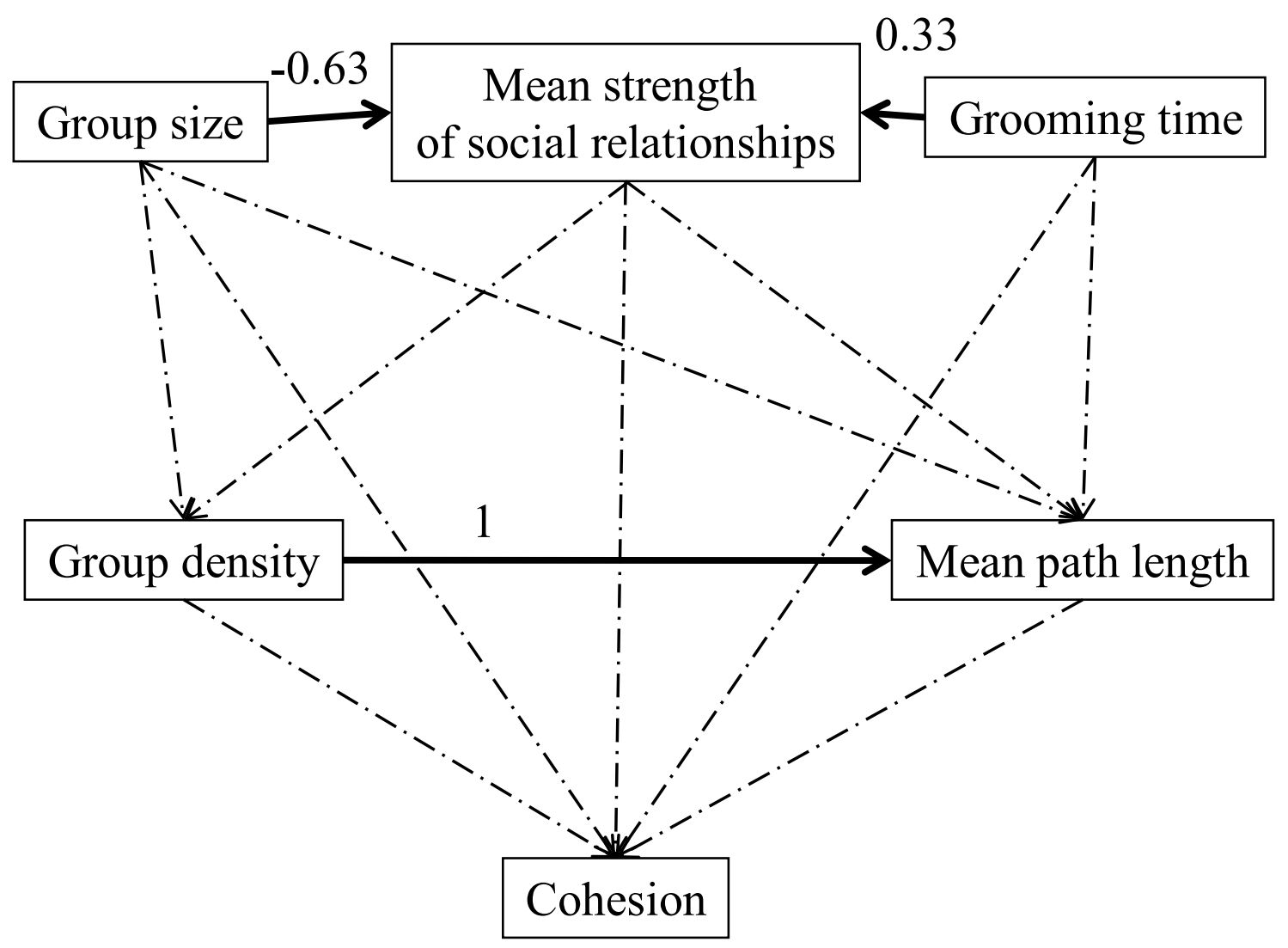

\section{a. Hypothesis 3}

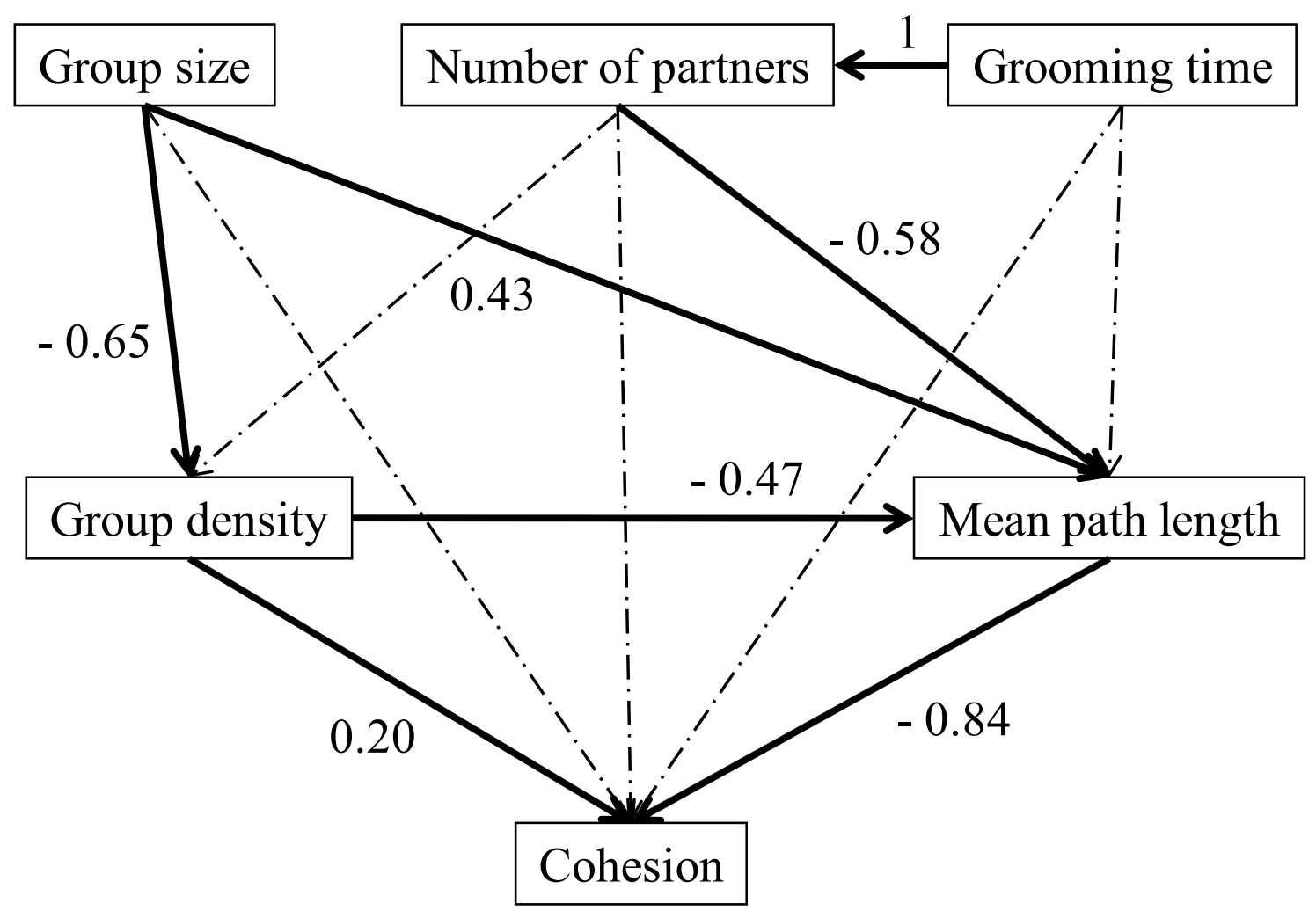

